\title{
La femineidad como máscara
}

Joan Rivière

\section{Traducción: Adriana Velásquez y María Ponce de León}

(Publicación original: Rivière, Joan. (1929). Womanliness as a mascarade. International Journal of Psycho-Analysis, $X$, 303-313).

Cualquiera sea el rumbo que haya tomado la investigación psicoanalítica parece haber atraído una y otra vez el interés de Ernest Jones, y dado que en los últimos años las investigaciones han comenzado a abordar el desarrollo de la sexualidad femenina, no cabe duda de que su contribución a la materia estará entre las más importantes. Como es habitual, Jones expone su trabajo con gran nitidez, utilizando el talento que lo caracteriza para aclarar el conocimiento que ya teníamos y enriquecerlo con nuevas observaciones.

En su artículo "The early development of female sexuality"1 , este autor esboza una clasificación de los distintos tipos de desarrollo femenino que divide, en primer lugar, en heterosexual y homosexual, y posteriormente divide éste último en dos tipos. Jones reconoce la naturaleza poco precisa y esquemática de su clasificación y postula un número de tipos intermedios. Uno de estos tipos intermedios es el que me interesa tratar en este momento. A diario, encontramos hombres y mujeres que, aunque presentan un desarrollo mayoritariamente heterosexual, manifiestan abiertamente fuertes rasgos del sexo opuesto. Esto ha sido juzgado como una expresión de bisexualidad inherente a todos nosotros; y el análisis ha demostrado que lo que parecen manifestaciones sexuales, o rasgos característicos homosexuales o heterosexuales son el resultado de una interacción de conflictos y no necesariamente la prueba de una tendencia innata o fundamental. La diferencia entre el desarrollo homosexual y heterosexual está determinada por los diferentes grados de angustia, con su correspondiente efecto en el desarrollo. Ferenczi señaló una reacción similar con respecto al comportamiento ${ }^{2}$; concretamente, que los hombres homosexuales exageran su heterosexualidad como una forma de "defensa" contra su homosexualidad. Intentaré demostrar que las mujeres que aspiran a la masculinidad pueden adoptar la máscara de la femineidad para evitar la angustia y las represalias que temen de los hombres.

Me ocuparé de un tipo particular de mujer intelectual. No hace mucho tiempo la búsqueda intelectual de las mujeres estaba asociada casi exclusivamente con un tipo de mujer abiertamente masculino que, en casos marcados, no escondía su deseo o derecho de ser un hombre. Esto ahora ha cambiado. De todas las mujeres que actualmente trabajan de manera profesional, sería difícil decidir si la mayoría de ellas son más femeninas que masculinas en sus personalidades y estilos de vida. En el medio académico o científico, así como en los negocios, constantemente se encuentran mujeres

\footnotetext{
${ }^{1}$ Jones, Ernest. (1927). The early development of female sexuality. International Journal of PsychoAnalysis, 8, 459-472.

2 Ferenczi, Sandor. (1916). The nosology of male homosexuality. En Richard Badger (Ed.). Contributions to Psycho-Analysis. Boston.
} 
que parecen cumplir con todos los criterios del desarrollo femenino completo. Son excelentes esposas y madres; son amas de casa competentes; mantienen una rica vida social y cultural; no carecen de intereses femeninos, por ejemplo, en su aspecto físico; y cuando son requeridas, incluso tienen tiempo para ejercer el rol de sustituto materno, devoto y desinteresado, entre un amplio círculo de parientes y amigos. Al mismo tiempo, cumplen con las obligaciones de su profesión al menos igual de bien que el hombre medio. Es realmente un enigma saber cómo clasificar psicológicamente este tipo de mujeres.

Hace algún tiempo, en el análisis de una mujer de estas características, realicé unos descubrimientos interesantes. Esta mujer se ajustaba casi exactamente a la descripción que acabo de dar: tenía una relación excelente con su marido, que incluía unos lazos íntimos muy estrechos entre ellos y frecuentes relaciones sexuales placenteras; se sentía orgullosa de su capacidad para realizar las tareas del hogar. Toda su vida había ejercido su profesión con gran éxito. Poseía un alto grado de adaptación a la realidad y lograba mantener buenas y apropiadas relaciones con casi todas las personas con las que establecía contacto.

Sin embargo, ciertas reacciones en su vida mostraron que su estabilidad no era tan perfecta como parecía. Una de estas reacciones servirá para ilustrar este tema. Se trataba de una mujer norteamericana dedicada a un trabajo de tipo propagandístico, que consistía principalmente en hablar y escribir. Durante toda su vida había experimentado cierto grado de angustia, a veces incluso muy severo, después de realizar algún acto público como hablar delante de un auditorio. A pesar de su incuestionable éxito y capacidad, tanto intelectual como práctica; y su habilidad para controlar al auditorio, dirigir los debates, etc., a la noche, se sentía agitada y aprensiva; tenía dudas respecto de si había hecho algo inapropiado y estaba obsesionaba con una necesidad de afirmación. En tales ocasiones, esta necesidad la llevaba compulsivamente a buscar la atención o los elogios de uno o varios hombres cuando finalizaba el acto en el que ella había participado o había sido la protagonista. Pronto se hizo evidente que los hombres que ella elegía para tal propósito siempre representaban, sin lugar a dudas, figuras paternas, aunque a menudo no eran personas cuyas opiniones acerca de su actuación tuvieran en realidad mucha importancia. Buscaba claramente dos tipos de afirmación en estas figuras paternas: el primero, una afirmación directa de su actuación mediante los cumplidos; el segundo y más importante, la afirmación indirecta mediante las atenciones sexuales de estos hombres. Para decirlo en términos generales, el análisis de su comportamiento luego de sus intervenciones desveló que intentaba obtener insinuaciones sexuales de este tipo particular de hombres flirteando y coqueteando con ellos de una manera más o menos encubierta. Esta conducta, que sobrevenía tan deprisa, era extraordinariamente incongruente con la actitud altamente impersonal y objetiva que mostraba durante su desempeño intelectual, lo cual planteaba un verdadero problema.

El análisis mostró que la situación edípica de rivalidad con su madre era extremadamente intensa y nunca había sido resuelta de manera satisfactoria. Más adelante volveré sobre este aspecto. Sin embargo, además del conflicto con su madre, la rivalidad con su padre era también muy notoria. Su trabajo intelectual, que tomaba forma en el habla y la escritura, se basaba en una identificación evidente con el padre, que primero había sido un hombre de letras y luego se había volcado a la política; su adolescencia se había caracterizado por una rebeldía consciente contra él, con sentimientos de rivalidad y de desprecio. El análisis frecuentemente revelaba sueños y fantasías de esta índole en los que castraba a su marido. Era bastante consciente de los sentimientos de rivalidad y de superioridad hacia muchas de estas figuras paternas, de quienes buscaba el apoyo después de 
sus propias actuaciones. Se sentía herida cuando insinuaban que no era igual a ellos y, en privado, rechazaba la idea de estar sujeta a sus juicios o críticas. En este aspecto corresponde claramente con uno de los tipos descritos por Ernest Jones: el primer grupo de mujeres homosexuales que, si bien no se interesan por las demás mujeres, desean la «aceptación» de su masculinidad por parte de los hombres y sostienen que son sus iguales o, en otras palabras, que son uno de ellos. Su resentimiento, sin embargo, no se expresaba abiertamente; en público, reconocía su condición de mujer.

El análisis reveló más tarde que sus miradas insinuantes y coquetería compulsivas, de las cuales ella no era realmente consciente hasta que el análisis las puso de manifiesto, se debían a lo siguiente: era un intento inconsciente de evitar la angustia que vendría a continuación debido a las represalias que anticipaba de parte de las figuras paternas luego de su despliegue intelectual. La demostración pública de su capacidad intelectual, que era llevada a cabo con éxito, significaba una exhibición de ella misma en posesión del pene del padre, que había sido castrado. Una vez finalizada la exposición, era presa de un terror espantoso por el castigo que su padre luego le impondría. Evidentemente esto propiciaba que pugnara por ofrecerse sexualmente al vengador. Esta fantasía, como se manifestó más tarde, había sido recurrente en su infancia y juventud, transcurridas en el sur de los Estados Unidos: en el caso de que un negro se aproximara para atacarla, planeaba defenderse obligándolo a besarla y a hacerle el amor (de tal manera que ella pudiera entregarlo luego a la justicia). Sin embargo, existía otro factor determinante de este comportamiento obsesivo. En un sueño que tenía un contenido muy similar a esta fantasía de la infancia, ella estaba sola en su casa, aterrorizada; un negro entraba y la encontraba lavando ropa, con la camisa arremangada y los brazos expuestos. Ella se resistía, con la secreta intención de atraerlo sexualmente y él comenzaba a admirar y acariciar sus brazos y sus pechos. Este sueño significaba que ella había matado al padre y a la madre y se había quedado con todo (sola en la casa), sentía pánico por el castigo que recibiría (esperaba disparos a través de las ventanas) y se defendía asumiendo un rol servicial (lavando ropa) y lavando la suciedad y el sudor, la culpa y la sangre, borrando todas las consecuencias de sus actos, y «disfrazándose» de mujer castrada. Bajo ese disfraz, el hombre no encontraba en ella ningún bien robado por el que debiera atacarla para poder recuperarlo y, más aún, la encontraba atractiva como objeto de amor. Así, el objetivo de la compulsión no era sólo sentirse reafirmada al despertar en el hombre sentimientos afectuosos hacia ella; sino que era, principalmente, ponerse a salvo disfrazándose de alguien inocente e inofensivo. Era una inversión compulsiva de su actuación intelectual; y los dos aspectos formaban la "doble acción" de un acto obsesivo, al igual que toda su vida consistía alternativamente de actividades masculinas y femeninas.

Antes de este sueño, había tenido otros donde aparecían personas que cubrían sus rostros con máscaras para impedir algún desastre. En uno de estos sueños, había una alta torre en una colina que se desplomaba sobre los habitantes de una aldea situada más abajo, pero como se ponían máscaras, salían ilesos.

La femineidad, por lo tanto, podía ser asumida y utilizada como una máscara para ocultar la posesión de la masculinidad, así como para evitar las temidas represalias que se tomarían contra ella si esto se llegara a descubrir; al igual que un ladrón vacía sus bolsillos y pide ser registrado para demostrar que no ha robado nada. El lector podrá tal vez preguntarse ahora cómo defino la femineidad o dónde trazo la línea que separa la genuina femineidad de la «máscara». Sin embargo, mi opinión es que no existe tal distinción; ya sea de manera radical o superficial, son una misma cosa. La femineidad estaba en esta mujer, y se podría incluso decir que existe hasta en la mujer más homosexual, pero 
debido a sus conflictos no representaba la línea principal de su desarrollo, por lo que era utilizada más como un recurso para eludir la angustia que como un modo primario de disfrute sexual.

Presentaré algunos detalles para ilustrarlo. Esta mujer había contraído matrimonio tardíamente, a los veintinueve años; había sentido gran angustia con respecto a la desfloración y una mujer médico le había hecho una incisión en el himen antes de la boda. Su actitud hacia las relaciones sexuales antes del matrimonio consistía en una determinación firme a obtener y experimentar el goce y el placer que, según sabía, algunas mujeres tenían, y a disfrutar del orgasmo. Temía a la impotencia exactamente de la misma manera que un hombre. Esto representaba en parte una decisión de superar ciertas figuras maternas frígidas, pero en un nivel más profundo era una determinación a no ser vencida por el hombre ${ }^{3}$. En efecto, el goce sexual era completo y frecuente, con orgasmo completo, pero resultó que la gratificación tenía el carácter de una afirmación y una restitución de algo perdido, y no de puro goce. El amor del hombre le devolvía su autoestima. Durante el análisis, mientras los impulsos castradores hostiles contra su marido estaban en proceso de ser manifestados, el deseo sexual se aplacaba considerablemente, y tuvo periodos de frigidez relativa. La máscara de la femineidad estaba desgastándose y revelándola castrada (sin vida, incapaz de sentir placer) o deseosa de castrar (por lo tanto temerosa de recibir el pene por medio de la gratificación). En una ocasión, durante un periodo en el que su marido tuvo una aventura amorosa con otra mujer, ella había reconocido una identificación muy intensa con él respecto de su rival. Resulta sorprendente que no hubiera tenido experiencias homosexuales (desde antes de la pubertad con una hermana menor), pero el análisis reveló que esta falta era compensada por sueños homosexuales frecuentes con orgasmos intensos.

En la vida diaria se puede observar cómo la máscara de la femineidad adopta formas curiosas. Conozco a una ama de casa competente, una mujer muy hábil, capaz de desempeñar tareas típicamente masculinas. Pero cuando llega a su casa, por ejemplo, un tapicero o un albañil, se siente obligada a ocultarle todos sus conocimientos técnicos, se muestra deferente y le hace sugerencias de una forma inocente e ingenua, como si sus comentarios fueran "casuales". Ella me ha confesado que incluso ante el carnicero y el panadero, a quienes en realidad controla con mano de hierro, no puede adoptar abiertamente una postura firme; se siente como si estuviera «representando un papel» y finge ser una mujer más bien sin instrucción, tonta y confusa que, sin embargo, al final, siempre se sale con la suya. En todas las demás relaciones, esta mujer es una señora culta y gentil, inteligente y bien informada y puede manejar sus asuntos a través de un comportamiento racional sensato sin acudir a subterfugios. Esta mujer tiene ahora cincuenta años, pero me cuenta que cuando era joven sentía una gran angustia cuando se relacionaba con camareros, taxistas, dependientes o cualquier otro tipo de figuras paternas potencialmente hostiles como médicos, albañiles o abogados; además, con frecuencia, discutía y tenía altercados con ellos, acusándolos de haberla estafado y cosas por el estilo.

Otro ejemplo de la vida cotidiana es el de una mujer inteligente, esposa y madre, catedrática universitaria de una asignatura abstrusa de aquellas que rara vez atraen a las mujeres. Cuando está dictando una conferencia, dirigida no a los estudiantes sino a sus colegas, escoge atuendos particularmente femeninos. Su comportamiento, en esas ocasiones, está marcado por un rasgo inapropiado: se torna irreverente y burlona, tanto que suscita comentarios y reproches. Cuando

\footnotetext{
${ }^{3}$ He encontrado esta actitud en varias mujeres analizadas y esta determinación de ser desfloradas en casi todas ellas (cinco casos). A la luz del Tabú de la virginidad de Freud, este último acto sintomático es bastante instructivo.
} 
demuestra su masculinidad a los hombres, lo hace como si fuera un «juego», como algo irreal, como una «broma». No puede tomar en serio el tema abordado; no puede verse a sí misma en un plano de igualdad con los hombres. Además, su actitud irreverente permite que se manifieste algo de su sadismo, de ahí el malestar que provoca.

Se podrían citar muchos otros ejemplos y, de hecho, he encontrado mecanismos similares en el análisis de hombres abiertamente homosexuales. Uno de estos casos era el de un hombre que padecía inhibición y angustia severas, para quien las actividades homosexuales quedaban relegadas a un segundo plano. Su mayor fuente de gratificación sexual era la masturbación en circunstancias especiales, concretamente, mientras se miraba al espejo vestido de una manera particular. La excitación se producía al verse a sí mismo con el cabello peinado con raya al medio y luciendo una corbata de lazo. Utilizaba estos «fetiches» extraordinarios para disfrazarse de su hermana; el peinado y el lazo eran de ella. Su actitud consciente era el deseo de ser una mujer, pero sus relaciones manifiestas con los hombres nunca habían sido estables. Inconscientemente, la relación homosexual resultaba ser completamente sádica y estaba basada en la rivalidad masculina. Las fantasías de sadismo y de "posesión de un pene" sólo se podían satisfacer cuando su imagen en el espejo le garantizaba que no iba a sentir angustia porque estaba a salvo "disfrazado de mujer".

Regresaré al caso que describí al comienzo. Bajo su heterosexualidad aparentemente satisfactoria, es obvio que esta mujer presentaba manifestaciones típicas del complejo de castración. Horney fue una de las primeras en señalar las causas de ese complejo en la situación edípica; en mi opinión, el hecho de que la femineidad pueda ser asumida como una máscara puede contribuir aún más al análisis del desarrollo femenino. Con esto en mente, esbozaré el desarrollo temprano de la libido en esta paciente.

Pero antes, debo explicar cómo eran sus relaciones con las mujeres. Ella era consciente de su rivalidad con casi cualquier mujer que tuviera buena apariencia o aspiraciones intelectuales. Era consciente de los arrebatos de odio que sentía hacia casi cualquier mujer con la que tenía algo en común, sin embargo, cuando se trataba de relaciones permanentes o cercanas era capaz de establecer relaciones muy satisfactorias. Inconscientemente, lo lograba, casi siempre, sintiéndose superior a las otras mujeres de un modo u otro (las relaciones con sus subordinados eran, en general, excelentes). Su habilidad como ama de casa se originaba mayormente en este hecho; así superaba a la madre, conseguía su aprobación y demostraba su superioridad entre las rivales "femeninas". Sus logros intelectuales, sin duda, tenían en parte la misma causa. Con ellos demostraba ser superior a la madre. Parece probable que al alcanzar la edad adulta, su rivalidad con las mujeres se intensificara mucho más en relación con los aspectos intelectuales que en lo referente a la belleza, ya que siempre podía refugiarse en su inteligencia para restarle importancia a la belleza.

El análisis reveló que estas reacciones, tanto hacia los hombres como hacia las mujeres, se originaban en la reacción hacia los padres durante la fase oral sádica. Estas reacciones se manifestaban en forma de fantasías, como las que expuso Melanie Klein en su ponencia para el Congreso de $1927^{4}$. La decepción o frustración durante la succión o el destete, asociadas a experiencias durante la escena primaria que se interpreta en términos orales, trae como

\footnotetext{
${ }^{4}$ Klein, Melanie. (1928). Early stages of the oedipus conflict. International Journal of Psycho-Analysis, 9, 167-180.
} 
consecuencia el desarrollo de un intenso sadismo hacia ambos padres ${ }^{5}$. El deseo de arrancar el pezón de un mordisco se sustituye por los deseos de destruir, penetrar y destripar a la madre, devorarla a ella y al contenido de su cuerpo. Este contenido incluye el pene del padre, las heces y los hijos; todas las posesiones y objetos de amor que se imaginan dentro del cuerpo de la madre ${ }^{6}$. El deseo de arrancar el pezón se sustituye también, como sabemos, por el deseo de castrar al padre arrancándole el pene de un mordisco. Ambos padres son rivales en esta etapa, ambos poseen objetos deseados; el sadismo está dirigido a los dos y se teme la venganza de ambos. Sin embargo, como siempre sucede con las niñas, la madre es la más odiada y, como consecuencia, la más temida. La madre inflingirá el castigo que corresponde al crimen: destruirá el cuerpo de la niña, su belleza, sus hijos, su capacidad para tener hijos; la mutilará, devorará, torturará y matará. En esta situación atroz, la niña sólo puede salvarse reconciliándose con la madre y expiando su crimen. Debe abandonar la rivalidad con la madre y hacer todo lo posible para restituirle lo que le ha robado. Como sabemos, ella se identifica con el padre y utiliza la masculinidad que así obtiene poniéndola al servicio de la madre. Se convierte en el padre y toma su lugar; de este modo puede «restituírselo» a la madre. Esta posición se ponía de manifiesto en muchas situaciones de la vida de mi paciente. Se deleitaba utilizando sus habilidades para ayudar a mujeres más débiles e indefensas que ella y podía mantener con éxito esta actitud siempre que la rivalidad no emergiera con demasiada intensidad. Pero esta restitución sólo podía realizarse con una condición: la de recibir una abundante recompensa en forma de gratitud y «reconocimiento». Deseaba el reconocimiento porque suponía que se le debía por sus sacrificios; de manera aún más inconsciente, lo que exigía era que se le reconociera su supremacía por poseer el pene que luego podría restituir. Si su superioridad no era reconocida, entonces la rivalidad se intensificaba inmediatamente; si la gratitud y el reconocimiento le eran negados, el sadismo estallaba con toda su fuerza y sufría (en privado) paroxismos de una furia oral sádica, igual que un bebé furioso.

Con respecto al padre, el resentimiento surgía de dos maneras: (1) durante la escena primaria le arrebataba a la madre la leche (etc.) que la niña necesitaba; (2) al mismo tiempo él le daba a la madre, y no a ella, el pene o los niños. Por consiguiente, ella debía quitarle todo cuanto poseía o acaparaba; lo castraba y reducía a la nada, igual que a la madre. El temor hacía él permanecía, aunque no tan intenso como el que sentía hacia la madre; en parte, porque esperaba que se vengara por la muerte y destrucción de la madre. Por lo tanto debía también apaciguar al padre. Para ello se disfrazaba con una máscara femenina, mostrándole su "amor" e inocencia. Es significativo que la máscara de esta mujer, aunque transparente para las otras mujeres, con los hombres funcionaba muy bien y cumplía su propósito. De este modo los atraía para sentirse aceptada. Una observación más detallada demostró que ese tipo de hombres tenían miedo de las mujeres extremadamente femeninas; preferían a una mujer que tuviera atributos masculinos, ya que sus exigencias eran menores.

En la escena primaria, el talismán que poseen ambos padres y que a ella le falta es el pene del padre; de ahí su rabia y, también, su terror e indefensión ${ }^{7}$. Si se lo arrebata al padre y lo posee,

\footnotetext{
${ }^{5}$ Jones, op. cit., p.469, considera que la característica principal del desarrollo homosexual en las mujeres es una intensificación de la fase oral sádica.

${ }^{6}$ Como no era esencial para esta discusión, he omitido toda referencia al desarrollo posterior de la relación hacia sus propios hijos.

${ }^{7}$ Cf. Searl, N. (1929). Danger Situations of the Immature Ego. Comunicación presentada en el Congreso de la British Psycho-Analytical Society, Oxford, Inglaterra.
} 
obtiene el talismán; la espada invisible, el "órgano del sadismo". El padre se vuelve impotente e indefenso (su dulce marido); sin embargo, ella aún se protege de su ataque llevando la máscara de la sumisión femenina y, bajo esa máscara, interpreta muchas de las funciones masculinas - "para él"(su sentido práctico y soltura). Lo mismo ocurre con la madre: una vez que le ha robado el pene, la ha destruido y reducido a una inferioridad lamentable, triunfa sobre ella, de nuevo en secreto; en apariencia reconoce y admira las virtudes de las mujeres «femeninas». Sin embargo, es más arduo protegerse de las represalias femeninas que de las masculinas, por ello sus esfuerzos por apaciguar y reparar el daño restituyendo y utilizando el pene al servicio de la madre nunca eran suficientes; ella utilizaba este recurso hasta el cansancio y, en ocasiones, la dejaba exánime.

Por consiguiente, parecía que esta mujer se había salvado a sí misma de la intolerable angustia que le ocasionaba la furia sádica contra ambos padres, creando en la fantasía una situación en la cual se convertía en un ser superior y nadie le podía hacer daño. La fantasía era la supremacía sobre los objetos paternos. A través de ésta, su sadismo se gratificaba, triunfaba sobre ellos. Con esta misma superioridad también lograba impedir sus venganzas mediante formaciones reactivas y ocultando su hostilidad. De este modo podía satisfacer al mismo tiempo las pulsiones del ello, su yo narcisista y su super-yo. Esa fantasía constituía el centro de toda su vida y su carácter, y estuvo cerca de llevarla a cabo hasta la perfección. Pero su punto débil era el carácter megalómano, bajo todos los disfraces, de la necesidad de supremacía. Cuando esta superioridad se veía seriamente perturbada durante el análisis, caía en un abismo de angustia, rabia y depresión; antes del análisis, caía enferma.

Me gustaría decir unas palabras sobre el tipo de mujer homosexual planteado por Ernest Jones, cuyo objetivo es obtener "reconocimiento" de su masculinidad por parte de los hombres. La pregunta que surge es si la necesidad de reconocimiento en ese tipo de mujer está relacionada con el mecanismo de la misma necesidad, pero que opera de otra forma (reconocimiento por los servicios realizados) en el caso que he descrito. En mi paciente, el reconocimiento directo de la posesión del pene no se exigía abiertamente; se exigía para las formaciones reactivas, aunque sólo la posesión del pene las hiciera posibles. Indirectamente, pues, lo que se exigía era el reconocimiento del pene. Esta forma indirecta se debía a su aprehensión ante la posibilidad de que su posesión del pene fuera "reconocida" o, en otras palabras, "descubierta". Está claro que con menos angustia mi paciente también habría reclamado el reconocimiento de los hombres por su posesión de un pene, y, de hecho, en privado, le mortificaba la ausencia de este reconocimiento directo, como sucede en los casos de Ernest Jones. Sin duda, en sus casos, el sadismo temprano obtiene mayor gratificación; el padre ha sido castrado y debe, incluso, aceptar su derrota. Pero entonces, ¿cómo evitan la angustia estas mujeres? En lo que respecta a la madre, la evitan, sin duda, negando su existencia. A juzgar por los indicios extraídos de los análisis que he llevado a cabo, concluyo que, en primer lugar, como Jones deja entrever, esta exigencia es simplemente una sublimación de la exigencia sádica original en la que el objeto deseado (ya sea el pezón, la leche o el pene) debe ser entregado inmediatamente. En segundo lugar, la necesidad de reconocimiento es, en gran medida, una necesidad de absolución. Ahora que la madre ha sido relegada al limbo, no es posible relacionarse con ella. Su existencia pareciera estar negada, aunque en realidad, es temida en exceso. Así que la culpa de haber triunfado sobre ambos padres sólo puede ser absuelta por el padre; si éste reconoce y aprueba la posesión del pene, ella está a salvo. Al otorgarle el reconocimiento, le otorga el pene, en lugar de a la madre; entonces ella lo posee, tiene el permiso para poseerlo y todo está en orden. El "reconocimiento" significa siempre, en parte, afirmación, autorización, amor; además, la convierte otra vez en un ser superior. Aunque él no lo sepa, para ella, el hombre ha admitido su derrota. En lo que se refiere al contenido, este tipo de relación fantástica con el padre es similar a la relación edípica normal; la 
diferencia reside en que la primera se construye sobre una base de sadismo. De hecho, ha asesinado a la madre y, por ello, no puede disfrutar de lo que la madre poseía; y lo que sí obtiene del padre, debe aún, en gran medida, arrebatárselo y arrancárselo.

Estas conclusiones nos obligan, una vez más, a plantearnos la pregunta: ¿Cuál es la naturaleza esencial de una femineidad completamente desarrollada? ¿Qué es das ewig Weibliche? La concepción de la femineidad como máscara, detrás de la cual el hombre sospecha algún peligro oculto, arroja un poco de luz sobre el enigma. La femineidad heterosexual completamente desarrollada está basada, como han señalado Helene Deutsch y Ernest Jones, en la fase oral de succión. La única gratificación de orden primario que se obtiene es la de recibir (el pezón, la leche) el pene, el semen, el hijo del padre. El resto depende de las formaciones reactivas. La aceptación de la «castración», de la humildad, de la admiración de los hombres, proviene, en parte, de la sobrestimación del objeto en el fase oral de succión; aunque, principalmente, procede de la renuncia (de una menor intensidad) de los deseos sádicos de castración que se derivan del nivel posterior, la fase oral de mordedura. "No debo tomarlo, no debo siquiera pedirlo; me lo deben dar". La capacidad de sacrificio, devoción y abnegación denota el esfuerzo para restituir y reparar, ya sea a las figuras maternas o paternas, lo que les ha sido robado. Es lo que Radó ha llamado un «seguro narcisista» de un valor inestimable.

Resulta evidente cómo la consecución de una heterosexualidad plena coincide con la obtención de la genitalidad. Y una vez más, podemos observar, como afirmó Abraham en un principio, que la genitalidad supone la consecución de un estado post-ambivalente. Tanto la mujer «normal» como la homosexual desean el pene del padre y se rebelan contra la frustración (o castración); pero uno de los aspectos que las diferencian es la intensidad del sadismo y la capacidad que tienen ambas para lidiar con él y con la angustia que éste les provoca.

\section{Formato de citación}

Rivière, Joan. (2007). La femineidad como máscara. Traducción de Adriana Velásquez y María Ponce de León. Athenea Digital, 11, 219-226. Disponible en http://psicologiasocial.uab.es/athenea/index.php/atheneaDigital/article/view/374/335.

Adriana Velásquez: Estudiante de Traducción e Interpretación en la Universitat Autònoma de Barcelona y licenciada en Antropología Social por la Universidad Central de Venezuela. Sus intereses engloban distintos ámbitos de la traducción entre los que destacan la traducción académica científicosocial y la traducción literaria.

María Ponce de León: Estudiante de Traducción e Interpretación en la Universitat Autònoma de Barcelona y diplomada en traducción literaria por la Universidad del Museo Social de Buenos Aires. Sus intereses engloban distintos ámbitos de la traducción entre los que destacan la traducción académica científico-social y la traducción literaria. 